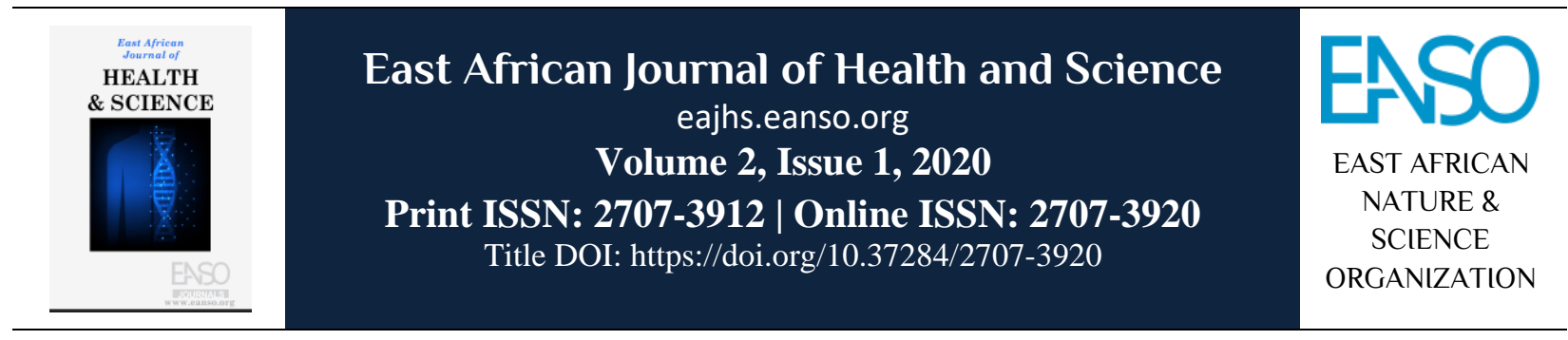

Original Article

\title{
Control of Diarrhoeal Diseases in Children in Kericho West Sub-County, Kenya
}

Japhet Kipngeno $^{1 *} \&$ John Ayieko Aseta ${ }^{2}$

${ }^{1}$ University of Kabianga, P. O. Box 2030 - 20200, Kericho, Kenya.

${ }^{2}$ Kaimosi Friends University College, P. O. Box 385 - 50309, Kaimosi, Kenya.

*Author for correspondence email: japhetkipngeno2013@gmail.com.

Article DOI: https://doi.org/10.37284/eajhs.2.1.145

\section{Date Published: ABSTRACT}

01 May 2020 Acute diarrheal disease among children aged less than five years remains a significant cause of morbidity and mortality worldwide. Severe infectious

Keywords: diarrhoea in children occurs most frequently under circumstances of poor environmental sanitation and hygiene, inadequate water supplies and poverty. In

Diarrhoeal, Kenya, the control of diarrhoea disease including the promotion of breastfeeding, Disease Control,

Sanitation,

Hygiene,

Breastfeeding,

Kericho. oral rehydration therapy and specific health education is a part of national strategies aimed to improve the quality of life and reduce the burdens caused by diseases. In Kericho West Sub-County, diseases associated with contaminated water, sanitation and poor hygiene tend to affect more in rural households. Nearly half of the children under five years suffer from related diarrhoeal diseases, thereby causing major concern to the entire local population. Therefore, this study aimed to determine the factors that lead to diarrhoeal diseases, to investigate the hygienic condition and source of water supply in the area, to examine the practices of the breastfeeding mothers and to determine the measures the county government has put in place to improve the health situation of the children. The study was grounded on two theories proposed by self-efficacy theory by Bandura. The study was carried out using a structured questionnaire as a quantitative tool while the interview guide was the qualitative tool for data collection. The location of the study was in Kericho West sub-county. The study concluded that there was a relationship between childhood diarrhoea, water, sanitation and hygiene in the study area. The study also found that there was a substantial positive association between breastfeeding and diarrhoea in children aged less than five years. From the findings, $83 \%$ used water with soap, while $41.3 \%$ obtained food from street vendors. The study recommends that the government facilities and private 
facilities should start sensitizing the Kericho West sub-county residents on the importance of maintaining hygiene through the use of clean and treated water as well as washing their utensils with hot water and soap. The government health care workers at the government facilities should counsel all the mothers and educate them on all the waterborne diseases as this would be the best option to control the communicable diseases in the County.

\section{APA CITATION}

Kipngeno, J., \& Aseta, J. (2020). Control of Diarrhoeal Diseases in Children in Kericho West Sub-County, Kenya. East African Journal of Health and Science, 2(1), 30-37. https://doi.org/10.37284/eajhs.2.1.145.

\section{CHICAGO CITATION}

Kipngeno, Japhet, and John Aseta. 2020. "Control of Diarrhoeal Diseases in Children in Kericho West Sub-County, Kenya". East African Journal of Health and Science 2 (1), 30-37. https://doi.org/10.37284/eajhs.2.1.145.

\section{HARVARD CITATION}

Kipngeno, J. and Aseta, J. (2020) "Control of Diarrhoeal Diseases in Children in Kericho West Sub-County, Kenya", East African Journal of Health and Science, 2(1), pp. 30-37. doi: 10.37284/eajhs.2.1.145.

\section{IEEE CITATION}

J. Kipngeno and J. Aseta, "Control of Diarrhoeal Diseases in Children in Kericho West Sub-County, Kenya", EAJHS, vol. 2, no. 1, pp. 30-37, May 2020.

\section{MLA CITATION}

Kipngeno, J., and J. Aseta. "Control of Diarrhoeal Diseases in Children in Kericho West Sub-County, Kenya". East African Journal of Health and Science, Vol. 2, no. 1, May 2020, pp. 30-37, doi:10.37284/eajhs.2.1.145.

\section{INTRODUCTION}

According to Ojewumi and Ojewumi (2012), diarrhoea prevalence continues to be alarming in Sub-Saharan Africa as a leading killer disease responsible for high morbidity and mortality, especially to children under the age of 5 years. This is especially so because of the region unique geographic, prevailing economic climate and poor health personnel and facilities as well as sociocultural factors. For this reason, though epidemiological statistics would have been expected to report a declining prevalence of diarrhoea from high rates of 30 to $50 \%$ worldwide, the case of sub-Saharan Africa continues to escalate with the rate as high as four mortality in a population of 10 households (Ejemot-Nwadiaro et. al., 2015). In the same vein, it is important to prompt a query on what could be the main cause of diarrhoea in this part of Africa making the region to be so vulnerable unlike other regions in Africa such as South or North Africa.

Inductive research by Ejemot-Nwadiaro et. al. (2015) noted that socioeconomic factors are the leading cause of the high prevalence of diarrhoea rather than cultural or geographic factors. The study established that the most devastating cause of diarrhoea as faecal, as the chef route of propagation of the menace. This is supported by a scientific background of the study which indicates that among the widest variant of pathogens indicates diarrhoea are species of bacteria, viral and protozoa that mainly emanate from the pathogens excreted from faeces which can be from humans or animals. Among the most important of these are Escherichia coli (E. coli), Salmonella, Shigella, Campylobacter jejuni, Vibrio cholera, Rotavirus, Nor virus, Giandia lamblia, Cryptosporidium and Entamoeba histolytica (WHO, 2009).

From a global perspective, it is imperative to know that diarrhoea is a major challenge across the universe. According to World Health Organization and UNICEF report of 2015 benchmarking of the global risk of diarrhoea showed that despite being a manageable disease, every year, the incidences of diarrhoea are in the range of 2 billion to 2.5 billion, about a quarter of the world population. Over $18.0 \%$ of the incidences are accounted for by children of the age of 5 years and below who most 
of them end up dying. When examined from different dimensions, this agrees with the WHO report in 2017 that more than 5,000 children die every day as a result of diarrhoeal disease worldwide and this is by a large extent in Africa.

Similarly, according to Schmidt and Cairncross (2009), it has been established that even though there is a high prevalence of diarrhoea amongst children under the age of 5 years seems in Africa, there are also serious incidences in Southeast Asian Countries which include Indonesia, Thailand, India, and Burma as well as in Latin America Nation. One study in Brazil established that the socioeconomic status of households seemed to be the biggest predictors of diarrhoea. Children aged under five years were found to be most affected especially twice the incidences were in households with a low economic background than the high economic background even though living as neighbors within the same localities (Moraes et. al., 2003)

Similar sentiments are expressed by Emch, Yunus, Escamilla, Feldacker and Ali (2010) and Clasen et al. (2012) who in different studies, one in Bangladesh and Haiti together with the Dominica Republic confirmed earlier report that households' socio-economic status (SES) rather than geographic and cultural factors explain incidences of diarrhoea more than the later. Even though the two acknowledge that though the global estimates of the incidences of diarrhoea continue to decrease from 5 Million in the 1980s and 1990s to 2.5 million in 2000s and currently at 2 million, the statistics are general overview with incidences being across countries and regions.

According to Emch et al. (2010) and Clasen et al. (2012),in spite of the reduction of poverty and increased innovation and advancement of health management from both curative and prevention approaches, the recent promotion of oral rehydration therapy (ORT) by individual countries all over the world in retrospect diarrhoeal disease continues to be considered amongst five majors killers of infants and children who are below five years.

According to Kericho County Health Department which is a devolved sector just like other counties across the country and especially in Kericho West
Sub-County, diarrhoea is recognized as among the top three leading causes of cases of out-patients proceeding malaria and poor diet which currently account to $16 \%$ of mortality of children aged under five years. This as elucidated by County Ministry of Health simply means than more than $80 \%$ of outpatients attendance is preventable and in an apparent reference to challenge which is manageable. The cases are by $100 \%$ caused by poor sanitation, water pollution and behaviours like eating without washing hands (Orora, 2013).

Successful research so far indicates that diarrheal disease in different parts of the world and especially in Sub-Sahara Africa continues to be a cause of concern. This has been established by different health and population statistics which offer very valuable insights into the current health status of people when correlated to other factors such as cultural, economic and social aspects of populations; this is more on the case of Kenya.

In Kericho West Sub-County, diseases associated with water pollution and the general hygiene of population affect more rural households. Shocking statistics indicate that in the range of half to above of infants and children who are below the age of 5 suffer from diarrhoeal related diseases, thereby causing a major concern for the entire local population (Orora,2013). The implied population, unfortunately, is not informed of the profound effects and what can be the outcome of these worsening situations. In a deeper sense, records in the County indicate a blink future of the entire SubCounty if this problem is not addressed. It is for this reason that the researchers took as an initiative to conduct research on this critical health issue.

\section{SELF-EFFICACY THEORY}

Self-efficacy theory by Bandura (1977) derives from a social cognitive theory that calls for behavioural change to enhance a personal sense of control and autonomy. It emphasizes self-efficacy, perception of oneself in being capable of performing certain actions to attain the desired outcome. The basis of this theory is that when people undertake initiatives to find a solution by themselves, they feel more inclined to take even more steps to solve such problems with more zeal and motivation. This theory makes a clarion call to 
communities to solve challenges connected with issues at hand with reference to poor sanitation, causing diarrhoeal amongst children under the age of 5 years. It also prompts for effective inwardlooking of solutions to the problem affecting the population without undermining solutions. The notable evidence shows that poor perception of the outcome of actions can be fatal hence perceived self-efficacy pertains to personal action control or agency (Wallston, 1992). In this case, it is expected that societies that will incentivize themselves to undertake measures to avert a problem would be more determined to address the problem to the finality

Based on self-efficacy theory, health-promoting behaviours may include hygiene practices related to water cleanliness, cleanliness of the surroundings of public standpipes, and storage tanks private household vendors, handling food, sanitation healthy breastfeeding practices require behaviour changes within a community.

A large body of research has examined the implications of optimistic self-efficiency beliefs as a predictor of behaviour change in the health paradigm (Maddux, \& Stanley, 1986). Behavioural change goals exert an effect through optimistic selfconfidence beliefs. These beliefs emphasize on perceived coping capabilities rather than simply reflect the existing ones. Therefore, expectancies of self-efficacy theory play an influential role in adopting good health behaviours, eliminating detrimental habits, and maintaining change. The researchers identify it as an engaging theory that can influence the practice of many in the implied population for better preventive behaviours, such as administration of self-breast examinations (Jirojwong \& Maclennan, 2003). Self-efficacy is crucial in both stages of the self-regulation of health behaviour. It is all about the positive attitude which encourages the decisions to change one's behaviour for a better outcome in regard to personal involvement with the problems affecting children aged less than five years.

\section{RESEARCH METHODOLOGY}

The research adopted a case study research design which is one in which information is collected without changing the environment. This is precisely because the study opted for spatial variation and temporal trends of diarrhoeal diseases as a phenomenon within a specified and limited location (Kericho West Sub-County). The purpose was to study in detail the nature and the causes of this phenomenon, including its effects on the local population. This allows for an inclusive assessment of diarrhoeal diseases of children less than five years of age, thereby indicating possible solutions to the problem of the study.

\section{Sampling and Sampling Techniques}

There are various strategies for determining sample size such as: using a census for a small population, use of sample size for a similar study, use of published tables and calculative method. Stratified sampling was used to divide the data into strata, and then in selecting the sample size, random sampling was employed from each stratum. To determine the size, Krejcie and Morgan (1970) sampling method were used. A portion of the sample size was computed; this proportion was used to determine the number of items in each stratum to be examined. The sample size was 264 respondents, comprised of 251 household heads and 13 medical personnel.

\section{Sampling Procedures}

The researchers opted for stratified sampling technique for the purpose of allotting the units for the study (Brewer, 1999). In the case of this study, parents (household heads) were randomly sampled from every third household to participate until the desired sample size of 251 households was obtained, as indicated in the table above. For medical personnel, purposive sampling procedures were used basically for credibility and efficiency purposes and not mere population representation and generalization. It also allows other sampling procedures to be used, for example, the selection of specialized people in the area. Purposive sampling for medical personnel was also used because the implied information fulfils criteria of the knowledge of the problem of diarrhoeal diseases. To realize its credibility and efficiency, this was done to obtain the sample size of 13 . 


\section{DISCUSSION OF RESEARCH FINDINGS}

A total of 252 out of 264 respondents took part in the account $95.5 \%$ of the sample size. According to Mugenda and Mugenda (2003), a response rate of $50 \%$ is adequate for analysis and reporting, $60 \%$ is good, and a response rate of $70 \%$ and over is excellent, and thus for this study, the response was excellent thereby ensuring good coverage of the respondents. The findings are presented in percentages and frequency distributions, as expressed in the subsequent tables.

Table 1: Social Demographic characteristics of the respondents

\begin{tabular}{llll}
\hline Characteristics & & Frequency & Percentage (\%) \\
\hline Age Bracket & Less than 25 years & 14 & 5.6 \\
& Between 26-30 years & 44 & 17.5 \\
& Between 31-35 years & 89 & 35.3 \\
& Between 36-40 years & 70 & 27.8 \\
& More than 41 years & 35 & 13.9 \\
\hline Gender & Male & 86 & 34.1 \\
& Female & 166 & 65.9 \\
\hline Education level & Primary education & 27 & 10.7 \\
& Secondary Education & 73 & 29.0 \\
& College education & 91 & 36.1 \\
& University education & 51 & 20.2 \\
& Postgraduate education & 10 & 4.0 \\
\hline Marital Status & Single & 62 & 24.6 \\
& Married & 172 & 68.3 \\
& Separated/Divorced/Widowed & 18 & 7.1 \\
\hline Occupation & Peasant & 56 & 22.2 \\
& Employed & 175 & 69.4 \\
& Self Employed & 21 & 8.3 \\
\hline Income (monthly) & Less than KSHS 10000 & 15 & 6.0 \\
& Between Kshs 10000 -20000 & 127 & 50.4 \\
& More than Kshs 20000 & 110 & 43.7 \\
\hline
\end{tabular}

The researcher sought for the background information of the respondents. The background information of respondents helps to determine whether the target population was suitable for the study, thereby authenticating the overall quality of analysis and findings (Mugenda and Mugenda, 2003).From the above respondents, it was established that majority $(35.3 \%)$ of the respondents were aged between 31-35 years followed by $27.8 \%$ who were between $36-40$ years. On gender, female respondents were the majority with $65.9 \%$ while on their education attained, $36.1 \%$ had a college education, followed by those with secondary education at $29 \%$. Further, the majority $68.3 \%$ of the respondents indicated that they were married while those that were single were $24.6 \%$. On the occupation of the respondents, it was established that $69.4 \%$ were employed and the majority earned between KES 10,000 to KES 20,000.

\section{Measures Taken by County Government to Improve Health of Children}

The research sought to establish measures that the county government of Kericho has put into place to improve the sanitary situation of the children and the findings are as shown in Table 2. 
Table 2: Measures Taken by County Government to Improve Health of Children

\begin{tabular}{lll}
\hline Characteristics & Frequency & Percentage (\%) \\
\hline Promoting immunization from waterborne diseases & 62 & 24.6 \\
The county government of Kericho has breastfeeding campaign & 190 & 75.4 \\
$\begin{array}{l}\text { Water, sanitation and hygiene (WASH) campaign in collaboration } \\
\text { with NGO's and CBOs }\end{array}$ & 77 & 30.6 \\
$\begin{array}{l}\text { It has promised to provide free care during childbirth as well as free } \\
\text { basic health services at public health facilities. }\end{array}$ & 175 & 69.4 \\
$\begin{array}{l}\text { Addressing the issue of a severe shortage of health workers, } \\
\text { Toilet per home campaign spearheaded by Governor }\end{array}$ & 62 & 24.6 \\
\hline
\end{tabular}

The research sought to establish measures that the county government of Kericho has put in place sufficient measures to improve the sanitary situation of the children. The county government promised to provide free care during childbirth as well as free basic health services at public health facilities. It was addressing the issue of a severe shortage of health workers and toilet per home campaign spearheaded by the Governor.

\section{Factors that Lead to Diarrhoeal Diseases}

The vast majority of the study participants perceived that childhood diarrhoea is caused by inadequate personal hygiene, inadequate knowledge on the causes and preventions methods by parents, and poor environmental sanitation. This clearly indicates that the local population and the medical staff had the correct understanding of the causes of childhood diarrhoea. The findings are also in line with the cultured by the presented tables. However, the medical staffs also indicated that most of the parents in the region associated the occurrence of childhood diarrhoea with the eruption of milk teeth, suckling hot breast milk, exposure to hot weather and feeding more breast milk. A 30 years old medical officer elaborates how hot weather causes diarrhoea as follows:

Some parents say that when their children are exposed to hot weather, they may get diarrhoea. Therefore, if the child is exposed to hot weather, he/she gets diarrhoea.

These findings clearly indicate the existence of the knowledge gap on the aetiology of childhood diarrhoea from the parents. Thus, the study discussion informs health officials and other stakeholders to develop better strategies to avoid these popular and sometimes unscientific misperceptions of the problem.

Many of the participants perceived that diarrhoea is one of the three most common childhood diseases in the study area. The morbidity data report of the district health office (Kericho County Ministry of Health Record book pg 28) indicated diarrhoea was among the top diseases. In relation to this point, a 36-year-old medical officer in the area who commented as follows:

The common childhood diseases in our village are malaria, diarrhoea and pneumonia. Diarrhoea hurts a child and it might lead to death. If the diarrhoea is bloody and a child does not get appropriate treatment soon, it can lead to death. In addition, a child with diarrhoea faces a loss of appetite and body weight. Therefore, diarrhoea has severe effects on child growth.

In contrast, a few of them indicated that diarrhoea was not a major health problem of children. These participants argued that diarrhoea should not be considered as a concern to child health and growth as most of the children got diarrhoea which resolved without any severe health problems. The participants perceived that the occurrence of diarrhoea is high during the rainy season, mainly because of the contamination of water sources.

Most of the health officers' patients proposed medications for mild cases of diarrhoea, which they use as first aid before they get a prescribed treatment at the nearby health facility. This treatment is available at health centres in the County. One of the health care professionals working in the clinic explained it as follows: 
The commonest homemade practice is giving boiled and cooled water with honey and, silver coin before bringing the sick children to us. Amazingly, the treatment works for them. They use this practice as first aid, i.e. to save the lives of their children before bringing to the clinic as they do have a problem of getting transport on time to bring their children to town. The mothers give this traditional treatment as long as their child is able to take/drink it. As the treatment has a metallic taste, some of the children may not drink it.

\section{CONCLUSION}

There is a significant association of diarrheal incidences of children aged less than five and point of use water treatment and safe storage. There are also locally available treatment methods which some are effective and others not. We can use that opportunity to promote water treatment and storage practices which are effective and still benefit from the gain of preventing diarrhoea among our children under the age of five years. The respondents had fair knowledge of the diarrhoea among children and this was based from the responses provided. The study revealed poor drinking water handling and storage within household, hand-washing without soap before food preparation and after defecation are major risk factors for diarrhoea among children less than five years. Inadequate sanitation factors such as presence of clogged drainage near/around the house and breeding places for flies/insects near the house increase the risk of diarrhoea among children less than five years. In all, hygiene practice among the mothers/caregivers of children with diarrhoea was poor. The study concludes that improvement in hygiene; water handling practices and sanitation within households are important factors in the elimination of diarrhoea. Majority were aware of diarrhoea among children as opposed by a quarter who were not. On the main symptoms of diarrhoea, it was established that majority cited unformed stool frequently. On the causative agent of the diarrheal, it was established that majority cited germs infection followed about a quarter who indicated worm infection. This translates that the respondents' knowledge was fair. Majority of the respondents indicated use of clean water as a diarrhoea prevention method. Majority of the households had a private pit latrine. The results show that children aged $0-5$ years who are exclusively breast fed are less likely to suffer from diarrhoea than infants who were not exclusively breastfed.

\section{RECOMMENDATION}

The research found that improving access to safe drinking of water and adequate sanitation as well as providing good hygiene, are key components in preventing diarrhoea. This can be summarized as follows; Health education should be provided on the importance of treating water by boiling and storing them in covered containers. Advocacy should be done on other effective methods of water treatment approved by WHO to replace less effective local methods currently practiced. Breastfeeding and immunization as protective measure. Breast-fed babies are much less likely to develop infectious diarrhoea compared to bottle-fed babies. Promotion of exclusive breast feeding in the first 4 to 6 months of life and reductions both in the incidence of diarrhoea and related deaths are likely to be beneficial for infant survival in this population. Regularly clean the toilets used, with disinfectant. Also, clean the flush handle, toilet seat sink taps, bathroom surfaces and door handles at least daily with hot water and detergent. Disposable cleaning cloths should be used (or a cloth just for toilet use). Make sure your child washes their hands after going to the toilet. Ideally, they should use liquid soap in warm running water but any soap is better than none. The government health care workers at the government facilities should counsel all the mothers and educate them on all the water borne diseases as this would be best option to control the communicable diseases in the county. The government facilities and private facilities should start sensitizing the Kericho residents on the importance of maintaining hygiene through use of clean and treated water as well as washing their utensils with hot water and soap. The advocacy on hand hygiene with detergent (soap) to children care takers should be emphasized as it protects the children against diarrhoea.

In conclusion, improvement in access to clean water and adequate sanitation along with the promotion of good hygiene practices, particularly 
hand washing with soap can help prevent childhood diarrhoea.

The study revealed that there is little research done on the diarrheal diseases and that the local population does not have adequate knowledge on the seriousness of the problem by diarrheal diseases in the sub-county. Therefore, there is a need for further research on this problem in order to create awareness of the root causes, preventive measures, better modern hygiene methods and general participation of the local population to respond to this critical issue.

\section{REFERENCES}

Bandura, A. (1977). Social cognitive theory and social referencing. In S. Feinman (Ed.), Social referencing and social construction of reality. New York: Plenum

Brewer, K. R. W. (1999). Design-based or prediction-based inference? Stratified random vs stratified balanced sampling. International Statistical Review, 67(1), 35-47.

Clasen, T., Fabini, D., Boisson, S., Taneja, J., Song, J., Aichinger, E., ...\& Nelson, K. L. (2012). Making sanitation count: developing and testing a device for assessing latrine use in lowincome settings. Environmental science \& technology, 46(6), 3295-3303.

Ejemot-Nwadiaro, R. I., Ehiri, J. E., Arikpo, D., Meremikwu, M. M., \& Critchley, J. A. (2015). Hand washing promotion for preventing diarrhoea. Cochrane Database of Systematic Reviews, (9).

Emch, M., Yunus, M., Escamilla, V., Feldacker, C., \& Ali, M. (2010). Local population and regional environmental drivers of cholera in Bangladesh. Environmental Health, 9(1), 2.

Jirojwong, S., \& MacLennan, R. (2003). Health beliefs, perceived self-efficacy, and breast selfexamination among Thai migrants in Brisbane. Journal of Advanced Nursing, 41(3), 241-249.

Krejcie, R. V. \& Morgan, D. W. (1970). Determining Sample Size for Research
Activities. Educational and Psychological Measurement, 30, 607-610.

Maddux, J. E., \& Stanley, M. A. (1986). Selfefficacy theory in contemporary psychology: An overview. Journal of Social and Clinical psychology, 4(3), 249-255.

Moraes, L. R. S., Cancio, J. A., Cairncross, S., \& Huttly, S. (2003). Impact of drainage and sewerage on diarrhoea in poor urban areas in Salvador, Brazil. Transactions of the Royal Society of Tropical Medicine and Hygiene, 97(2), 153-158.

Mugenda, O. M., and Mugenda, A.G. (2003). Research Methods: Quantitative and Qualitative Approaches. Nairobi: Acts Press.

Ojewumi, T. K., \& Ojewumi, J. S. (2012). Trends in Infant and Child Mortality in Nigeria: a wake-up call assessment for intervention towards achieving the 2015 MDGs. Science Journal of Sociology \& Anthropology, 1(2), 110.

Orora, C. N. (2018). Household Environmental Hazards and Behavioural Practices Influencing Children Diarrheal Incidences in Homabay County, Kenya (Doctoral Dissertation, MMUST).

Schmidt, W. P., \& Cairncross, S. (2009). Household water treatment in poor populations: is there enough evidence for scaling up now?. Environmental science \& technology, 43(4), 986-992.

Steffen, R. (2017). Epidemiology of travellers' diarrhoea. Journal of travel medicine, 24(suppl_1), S2-S5.

Wallston, K. A. (1992). Hocus-pocus, the focus isn't strictly on locus: Rotter's social learning theory modified for health. Cognitive therapy and research, 16(2), 183-199.

World Health Organization. (2009). Diarrhoea: why children are still dying and what can be done. 